\title{
Caracterização Física e Química de Terminalia catappa Linn, Utilizadas na Arborização de Áreas Urbanas de Cuité-PB
}

Dayana Moreira Leite*; (Graduanda em Química na Universidade Federal de Campina Grande)

Aline Priscila de F. Silva; (Graduanda em Química na Universidade Federal de Campina Grande)

Mônica Andrade de Mattos; (Mestranda do PPGCNBiotec, Universidade Federal de Campina Grande)

Ana Paula Moisés Sousa; (Mestranda do PPGCNBiotec, Universidade Federal de Campina Grande)

Renato Alexandre C. de Santana; (Prof. Adj. da UABQ e do PPGCNBiotec na Universidade Federal de

Campina Grande)

Ana Regina Nascimento Campos; (Profa. Adj. da UABQ e do PPGCNBiotec na Universidade Federal de Campina Grande)

*day_ana_leite@hotmail.com

\section{RESUMO:}

Originária da índia, a castanhola, cujo nome científico é Terminalia catappa Linn, uma espécie da família das Combretáceas, é uma árvore exótica distribuída nas regiões costeiras e bem adaptada às condições de clima e solos do Brasil, inclusive no semiárido nordestino. Embora seja bem difundida em solo brasileiro, estudos sobre a referida espécie ainda são bastante escassos na literatura. Este trabalho teve como objetivo realizar a caracterização física e química das castanholas ( $T$. catappa Linn) utilizadas na arborização das vias públicas da cidade de Cuité - PB, situada na região do Curimataú Paraibano. As partes constituintes desta espécie apresentadas neste trabalho foram folhas, frutos e a amêndoa, coletados de árvores em estado de frutificação existentes nas ruas da cidade. Os parâmetros físicos obtidos para os frutos foram: determinação de massas utilizando balança analítica; altura e diâmetros, usando paquímetro; e densidade fruto. Foram avaliados os seguintes parâmetros químicos: teor de água, resíduo mineral, pH, acidez titulável, Brix e teor de minerais. Os valores obtidos na caracterização física foram: peso médio do fruto $38,48 \mathrm{~g}$, altura $52,80 \mathrm{~mm}$, densidades $0,93 \mathrm{~g} / \mathrm{cm}^{3}$ e $0,99 \mathrm{~g} / \mathrm{cm}^{3}$. Os resultados obtidos nas análises químicas foram: teor de água 87,39\% (polpa), 32,29\% (amêndoa) 77,31\% (folha); pH 4,67 (polpa), 4,57 (folha); acidez 9,3\% (polpa), 10,29\% (folha); ${ }^{\circ}$ Brix 7,75; resíduo mineral $15,19 \%$ (folha); os teores de minerais encontrados na folha da castanhola foram K $(41.24 \%$ ), Ca $(32.84 \%)$, Fe $(32.84 \%)$ e P $(1.08 \%)$. A biometria determinada dos frutos da castanhola foi semelhante aos encontrados por outros autores. Foram encontrados altos teores de potássio, cálcio e ferro na folha da castanhola. A literatura consultada indica várias aplicações para castanhola seja nos aspectos, econômicos, medicinais e alimentar, no entanto, esta ainda é bastante subutilizada.

Pallavras-chave: Biometria; Fruto; Castanhola

Espaço reservado para organização do congresso.

\section{I ntrodução}


A Terminalia catappa Linn, pertencente à família Combretáceae, conhecida como castanholeira, chapéu-de-sol e mais popularmente de castanhola. É uma árvore nativa da Índia, com altura variando entre 25 e $45 \mathrm{~m}$. As espécies do gênero Terminalia são amplamente distribuídas em regiões tropicais e subtropicais (COLLINS; PILOTTI; WALLIS, 1992).

Diversos estudos têm sido realizados sobre as propriedades biológicas dessa espécie na saúde humana, tendo sido descritas várias atividades como anti-inflamatória, antitumoral, antiviral e antidiabética. As folhas da T. catappa Linn são utilizadas para fins terapêuticos, aproveitadas como forma de bebida (chá) (PETERSON; JOHNSON, 1978).

A fruta possui polpa comestível, apesar de muitas vezes não aproveitada, talvez por ser fibrosa e apresentada por muitas pessoas como não muito agradável. Dados sobre a composição química de alimentos não comuns ainda são praticamente insuficientes e o fruto da T. catappa Linn pode vir a se constituir uma opção para auxiliar a suplementação de dietas da população. A castanhola é um dos alimentos considerados sem importância para a população e através de pesquisas são encontrados altos valores nutricionais, mas para a maioria das pessoas são desprezados. O conhecimento da composição química de alimentos e o valor nutricional destes é de fundamental importância para várias atividades, tais como: o estabelecimento de dietas adequadas aos indivíduos, para recomendação de uma alimentação balanceada a grupos populacionais e desenvolvimento de novos produtos (LAJOLO et al., 1995).

Este trabalho avaliou a composição química e caracterização física de partes da Terminalia catappa Linn utilizadas na arborização de áreas Urbanas da cidade de Cuité - PB, considerando que a mesma pode vir a ser uma fonte alternativa de alimento natural que se encontra acessível.

\section{Material e Métodos}

Todo material coletado para realização deste trabalho foi obtido de forma aleatória das castanholas (Terminalia catappa Linn) situadas nas ruas do município de Cuité - PB, localizado na mesorregião do Agreste e microrregião do Curimataú Ocidental Paraibano, cujas coordenadas geográficas são $6^{\circ} 28^{\prime}$ 54'” de latitude sul e $36^{\circ} 8^{\prime}$ '59' de longitude oeste. Na classificação de Koppen o clima é do tipo BSwh', quente semiárido do tipo estepe (TERRITÓRIO DO CURIMATAÚ, 2010).

A obtenção dos frutos e folhas ocorreram nos meses de abril e setembro de 2015 e incluiu uma quantidade entre 20 e 25 frutos. Foram selecionadas amostras dos frutos utilizando-se a polpa e a amêndoa: 14 unidades para análises física, 4 unidades para determinação de densidade, 5 a 7 unidades aproveitados para extração da polpa e das amêndoas para realização das análises químicas. Todas as análises foram executadas no Laboratório de Bioquímica e Biotecnologia de Alimentos, no Campus de Cuité - CES/UFCG. Os frutos foram coletados conforme o estado de maturação em que são consumidos, a coleta foi efetuada de forma direta. O material foi higienizado em solução de água clorada por 15 minutos, lavados com água novamente e secos, posteriormente despolpados manualmente com auxílio de faca separando-se a polpa da semente (caroço), sendo posteriormente destinados a determinação das características físicas e químicas.

\subsection{Determinação das Características Físicas}

As características físicas do fruto in natura determinadas no estudo foram: massa total do fruto inteiro, massa da polpa, massa da semente (endocarpo) e massa da amêndoa (Fig. 1), usando-se balança analítica Scientech SA 210. Para avaliação dos dados biométricos relacionados à altura, diâmetro maior (eixo transversal) e diâmetro menor (espessura) usou-se paquímetro digital.

O fruto da castanheira é constituído por um pericarpo que é um tecido delgado, pouco esponjoso e de cor vinácea, por um mesocarpo, sendo este de aspecto carnoso, esponjoso e fibroso (IVANI, 2008).

Para determinação das densidades pesou-se o fruto inteiro da castanhola na balança para se obter a massa, para se obter o volume utilizou-se uma proveta com capacidade de $1000 \mathrm{~mL}$, adicionou-se $500 \mathrm{~mL}$ de água na mesma, logo após foi lançado cada fruto na proveta, cujo volume foi verificado pelo deslocamento da coluna de água. O mesmo procedimento foi repetido substituindo-se água por óleo. 


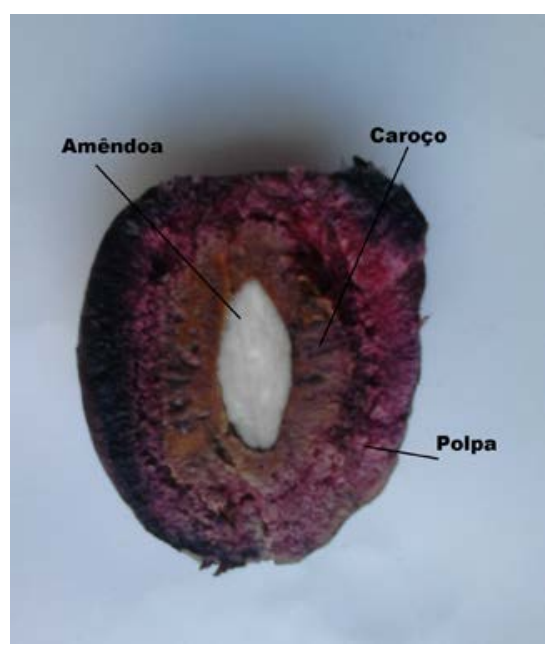

Figura 3. Partes do fruto avaliadas Fonte: Autora

\subsection{Determinação das Características Químicas}

Variáveis químicas determinadas no estudo de Terminalia catappa Linn foram:

a) Determinação de pH

Para as análises de $\mathrm{pH}$ foram triturados polpa e folhas da castanhola, separadamente, pesou-se aproximadamente $5 \mathrm{~g}$ de cada amostra em um becker, em seguida utilizando uma proveta adicionou-se $50 \mathrm{ml}$ de água destilada, depois a solução foi homogeneizada e realizada a leitura. As medidas de $\mathrm{pH}$ foram feitas em pHmetro Metromhm, calibrado com solução tampão de pH 7,0 e 4,0, onde o pH foi determinado através de medidas potenciométricas do líquido sobrenadante (IAL, 2008).

\section{b) Acidez titulável}

A acidez da polpa e da folha foram determinadas por volumetria, utilizando-se fenolftaleína como indicador ácido-base. Preparou-se soluções aquosas da polpa e das folhas transferindo-se para cada erlenmeyer $100 \mathrm{~mL}$ de água destilada e adicionando a este aproximadamente $5 \mathrm{~g}$ das amostras da polpa e das folhas, previamente triturada, posteriormente adicionou-se 3 gotas de fenolftaleína em cada erlenmeyer e titulou-se com solução de $\mathrm{NaOH}$ 0,1 M, sob agitação constante (IAL, 2008).

c) Determinação de teor de água

As amostras (polpa e a folha) foram triturados separadamente, logo após pesou-se aproximadamente 2 $\mathrm{g}$ da polpa, amêndoa e a folha em vidros de relógio, previamente tarados e em triplicatas. Posteriormente à pesagem à amostra foi aquecida em estufa a $105^{\circ} \mathrm{C}$, por $24 \mathrm{~h}$ (IAL, 2008); em seguida resfriou-se em dessecador até a temperatura ambiente, para depois se efetuar a pesagem final.

d) Determinação do teor de resíduo mineral

As amostras da folha foram trituradas e logo após pesou-se aproximadamente $5 \mathrm{~g}$ de cada amostra em balança analítica em cadinhos de porcelana, posteriormente foram aquecidas em forno mufla a $550^{\circ} \mathrm{C}$ (IAL, 2008), por 4horas, e resfriadas em dessecador até a temperatura ambiente e pesadas.

e) Determinação de ${ }^{\circ}$ Brix

Para análise de determinação de Brix as amostras da polpa foram trituradas e em seguida retirou-se o sumo da polpa e posteriormente utilizou-se refratômetro de Abbé, com escala graduada de Brix (pelo menos 0,5\%), calibrou com água destilada, adicionou algumas gotas no equipamento onde se fez a leitura. O grau Brix é a medida do índice de refração (IAL, 2008).

\section{f) Determinação de minerais por EDX}

Os minerais foram identificados e quantificados por Espectrômetro de Fluorescência de Raios-X por Energia Dispersiva, o equipamento utilizado foi o Shimadzu EDX-720 (EDX).

\section{Resultados e Discussão}




\subsection{Caracterização física}

Segundo Eniel, Martins e Carvalho (2001), estudos de caracterização física de frutos e sementes são importantes porque podem sinalizar diferenças entre espécies de mesmo gênero como também possibilitam comparações de uma espécie que habitam diferentes localidades geográficas.

Os resultados obtidos neste trabalho para a caracterização física dos frutos e sementes da castanhola estão exibidos na Tabela 1 . O peso médio do fruto da castanhola foi de $38,48 \pm 7,30 \mathrm{~g}$, valor aproximado ao de Cavalcante et al (1986), que obtiveram um peso médio de fruta inteira de 38,37g, e superior a 19,60g, encontrado por Marques et al (2012). Relacionado ao peso médio da semente, os mesmos autores obtiveram 20,23 e 7,28g, respectivamente, valores superiores ao encontrado neste estudo que foi $5,82 \pm 1,14 \mathrm{~g}$.

Na biometria dos frutos os resultados relacionados à altura foi de $52,80 \pm 2,36 \mathrm{~mm}$, diâmetro (maior) 47,24 $\pm 2,96 \mathrm{~mm}$, diâmetro menor 35,07 $\pm 2,82 \mathrm{~mm}$, de modo que se mostraram superiores quando comparados as médias dos valores encontrados por Marques (2012), comprimento 43,28mm, largura de 31,62 mm, espessura de 25,75 mm.

Uma possível justificativa para a discrepância entre os resultados encontrados pode estar relacionada à variabilidade, idade da arvore, condições de cultivo, clima, utilização de fertilizantes dentre (SOUTO et al., 2008).

A densidade do fruto da castanhola obtida utilizando a água foi $0,93 \mathrm{~g} / \mathrm{cm}^{3}$, portanto inferior a densidade da água cujo valor é $1,0 \mathrm{~g} / \mathrm{cm}^{3}$, observou-se que o fruto sobrenadou. Utilizando-se o mesmo procedimento com óleo de cozinha, obteve-se um resultado $0,99 \mathrm{~g} / \mathrm{cm}^{3}$ para o fruto, ao compara-lo ao do óleo que é $0,92 \mathrm{~g} / \mathrm{cm}^{3}$, o mesmo apresentou-se superior, observou se nesse caso que a castanhola ligeiramente submergiu.

Tabela 1- Valores das massas dos frutos (Terminalia catappa Linn) coletados na cidade de Cuité -PB

\begin{tabular}{|c|c|c|c|}
\hline Características Físicas & $\begin{array}{c}\text { Valor } \\
\text { Mínimo }\end{array}$ & $\begin{array}{c}\text { Valor } \\
\text { Máximo }\end{array}$ & Média* \\
\hline Massa Total (g) & 28,07 & 48,27 & $38,48 \pm 7,30$ \\
\hline Massa Polpa (mesocarpo) (g) & 21,16 & 40,37 & $32,13 \pm 6,92$ \\
\hline Massa caroço (endocarpo) (g) & 4,60 & 8,71 & $5,82 \pm 1,14$ \\
\hline Massa amêndoa (g) & 0,37 & 0,63 & $0,51 \pm 0,07$ \\
\hline Altura (mm) & 49,44 & 56,64 & $52,80 \pm 2,36$ \\
\hline Diâmetro maior (mm) & 42,15 & 51,13 & $47,24 \pm 2,96$ \\
\hline Diâmetro menor (mm) & 30,60 & 38,93 & $35,07 \pm 2,82$ \\
\hline Densidade нго $\left(\mathrm{g} / \mathrm{cm}^{3}\right)$ & 0,92 & 0,95 & $0,93 \pm 0,02$ \\
\hline Densidade óleo $\left(\mathrm{g} / \mathrm{cm}^{3}\right)$ & 0,92 & 1,05 & $0,99 \pm 0,06$ \\
\hline
\end{tabular}

\subsection{Caracterização Química}

Para as características químicas, conforme Tabela 2, o teor de água para a polpa foi $87,39 \pm 0,16 \%$, para folha 77,31 $\pm 0,28 \%$ e para amêndoa 32,29 $\pm 1,72 \%$, com teores superiores aos observados por Lima (2012) ao verificar os teores das partes comestíveis, obtendo para polpa 83,25 $\pm 0,25 \%$, para amêndoa $12,96 \pm 0,13 \%$. A diferença da umidade da amêndoa pode ser devida a influência de algum fator ambiental ou por período de frutificação.

Nesta Tabela estão expressos os valores de $\mathrm{pH}$ da polpa 4,67 $\pm 0,03$ e da folha 4,57 $\pm 0,03$, valor da polpa próximo ao encontrado por Lima (2012), que obteve $\mathrm{pH}(4,85 \pm 0,05)$, conferindo um caráter mais ácidos para estas estruturas do fruto da castanhola. 
Os resultados de acidez titulável da polpa da castanhola foi de $9,3 \pm 1,81 \%$, que comparado ao valor encontrado por De Paula (2008) mostra-se semelhante (7,94+4,41\%). O valor da acidez titulável encontrado para a folha da castanhola foi de $10,29 \pm 0,79 \%$.

Tabela 2 - Dados da caracterização química das partes da castanhola (Terminalia catappa Linn)

\begin{tabular}{cccc}
\hline $\begin{array}{c}\text { Composição } \\
\text { centesimal }\end{array}$ & Polpa & Amêndoa & Folha \\
\hline Teor de água (\%) & $87,39 \pm 0,16$ & $32,29 \pm 1,72$ & $77,31 \pm 0,28$ \\
\hline Resíduo mineral (\%) & & - & $15,19 \pm 1,5$ \\
\hline pH & $4,67 \pm 0,03$ & - & $4,57 \pm 0,03$ \\
\hline Acidez Titulável (\%) & $9,3 \pm 1,81$ & - & $10,29 \pm 0,79$ \\
\hline Brix & 7,75 & - & \\
\hline
\end{tabular}

O teor de sólidos solúveis encontrado por Marques et al. (2012) para o fruto da castanhola foi $8^{\circ}$ Brix, próximo ao encontrado nesta pesquisa $7,75^{\circ}$. Os sólidos solúveis são compostos por açúcares, cujo teor varia com a espécie, a forma de cultivo, o estágio de maturação e o clima, com valores médios entre 8 e 14\% (CHITARRA; CHITARRA, 2005). O ${ }^{\circ}$ Brix é utilizada na fabricação de doces, sucos, polpas e bebidas em geral (COSTA et al., 2004). As matérias-primas serão tanto melhores para a industrialização quanto maiores forem os seus teores de SST (CHITARRA; CHITARRA, 2005).

Para Krause e Mahan (1991) os minerais desempenham diversos papéis essenciais no organismo, tanto na sua forma iônica em soluções nos fluidos corporais, quanto como constituintes de compostos essenciais. Eles também atuam como cofatores enzimáticos, sendo, portanto, requeridos em quantidades que dependem da fase de crescimento, das condições fisiológicas (gravidez, lactação) do estado nutricional e da saúde. Além disso, regula o equilíbrio ácido-base, a pressão osmótica, as atividades musculares e nervosas facilitam a transferência de compostos essenciais através das membranas e, em alguns casos, fazem parte dos elementos constituintes dos tecidos do organismo (CHIES et al. 1994 apud TEIXEIRA, 2010).

A Tabela 3 apresenta os teores dos elementos minerais encontrados na folha castanhola. Os altos teores deparados nas análises de teor de minerais da folha foram: (K- 41,24\%, Ca 32,84\% e Fe-15,02\%). Os minerais encontrados na folha são consideravelmente acentuados na alimentação e segundo Peterson et al. (1978) o consumo pode ser feito na forma de chá das folhas da castanhola.

Tabela 3- Teor de Minerais encontrados na castanha da Folha T. catappa Linn

\begin{tabular}{lllll}
\hline Minerais & K & Ca & Fe & P \\
\hline Teor (\%) & 41,24 & 32,84 & 15,02 & 1,08 \\
\hline
\end{tabular}

\section{Conclusão}

A biometria determinada dos frutos da castanhola foi semelhante às encontradas por outros autores.

Foram encontrados altos teores de potássio, cálcio e ferro nas folhas da castanhola.

A literatura consultada indica várias aplicações para castanhola seja nos aspectos, econômicos, medicinais e alimentar, no entanto esta ainda é bastante subutilizada. 


\section{Physical and chemical characterization of the Terminalia catappa Linn, utilized in afforestation of the urban areas of Cuité-PB}

Abstract: Originally from India, the castanets, whose scientific name is Terminalia catappa Linn, a species of the family of Combretáceas, is an exotic tree distributed in coastal regions and well adapted to the climate conditions and soils of Brazil, including in the semi-arid northeast. While it is widespread in Brazilian soil, studies of the species are still quite scarce in the literature. This study aimed to carry out physical and chemical characterization of castanets (T. catappa Linn) used in the afforestation of public roads of the city of Cuité - PB, located in Curimataú Paraiba region. The constituent parts of this species presented in this paper were leaves, fruits and kernels collected from trees in a state of existing fruiting on city streets. The physical parameters obtained for the fruits were: determination of masses using analytical balance; height and diameter, using caliper; and density result. We evaluated the following chemical parameters: water content, mineral residue, $\mathrm{pH}$, titratable acidity, Brix and minerals content. The values obtained in the physical characterization were: average fruit weight $38.48 \mathrm{~g}, 52.80$ $\mathrm{mm}$ height, density $0.93 \mathrm{~g} / \mathrm{cm}^{3}$ and $0.99 \mathrm{~g} / \mathrm{cm}^{3}$. The results of chemical analyzes were: water content 87.39\% (pulp), 32.29\% (almond) 77.31\% (leaf); pH 4.67 (squash), 4.57 (leaf); acidity 9.3\% (pulp), $10.29 \%$ (leaf); $7.75^{\circ}$ Brix; mineral residue $15.19 \%$ (leaf); the mineral levels found in castanets leaf were K (41.24\%), Ca (32.84\%), Fe (32.84\%) and P (1.8\%). At one biometry of the fruits of castanets it was similar to those reported by other authors. Found high levels of potassium, calcium and iron in the castanet sheet. The literature indicates various applications for castanet is in, economic, medicinal and food, however, this is still quite underutilized

Keywords: Biometry; Fruit; Castanets

\section{Referências bibliográficas}

CAVALCANTE, M. A. et al. Características físicas químicas da Castanhola, Terminalia catappa Linn, Ciência Agronômica, v. 17, n. 1, p. 111-116. 1986.

CHItARRA, M. I. F.; CHITARRA, A. B. C. Pós-colheita de frutas e hortaliças: fisiologia e manuseio. 2 ed. Lavras: UFLA, 2005, 785p.

COLLINS, D.J.; PILOTTI, C.A.; WALLIS, F.A.; 1992. Triterpene acids from some Papua New Guinea Terminalia species. Phytochemistry 32 (3), 881-884.

COSTA, W. S. da, FILHO, J. S., MATA, M. E. R. M. C., QUEIROZ, A. J. de M. Influência da concentração de sólidos solúveis totais no sinal fotoacústico de polpa de manga. Revista Brasileira de Produtos Agroindustriais, v.6, n.2, p.141-147, 2004.

DE PAULA, A. A. Caracterização físico-química e avaliação do potencial antioxidante dos frutos da Terminalia catappa Linn/ Andréia Alves de Paula. -Itapetinga: Universidade Estadual do Sudoeste da Bahia, (Dissertação Mestrado) - Programa de Pós-Graduação em Engenharia de Alimentos, 91p. 2008.

ENIEL, D. C.; MARTINS, F. O.; CARVALHO, J.E.U. Biometria de sementes e germinação de jatobácuruba (Hymenaea intermédia Ducke, Leguminoseae-Caesalpinioideae). Revista Brasileira de Botânica. São Paulo, v.4, n.2, p.1-6, 2001.

M.L.P. MELO; G.A. MAIA; A.P.V. SILVA; G.S.F. OLIVEIRA; R.W. FIGUEIREDO. Caracterização físico-química da amêndoa da Castanha de caju (Anacardium Occidentale L.) Crua E Tostada. Ciência e Tecnologia de Alimentos, vol. 18 n. 2 Campinas Maio/Junho 1998. 
INSTITUTO ADOLFO LUTZ (São Paulo). Métodos físico-químicos para análises de alimentos. Coordenadores: Odair Zenebon; Neus Sadoco Pascuet \& Pablo Tigea. São Paulo, Ed. 4, $1^{\text {a }}$ Edição Digital, 2008.

IVANI, S. A.; SILVA, B. M. S.; OLIVEIRA, C.; MÔRO, F. V. Morfologia de frutos, sementes e plântulas de castanheira (Terminalia catappa L. - Combretaceae). Revista Brasileira de Fruticultura. Jaboticabal, vol.30, n. 2, 2008.

KRAUSE, M. V.; MAHAN, L. K. Alimentos, nutrição e dietoterapia. São Paulo: Livraria Roca, 981p ,1991.

LAJOLO, F. M. As deficiências da composição de alimentos no Brasil. Simpósio das Instituições de Alimento e Nutrição. 2-5 p, 1995.

LIMA, R. M. T. de, Fruto da castanhola (Terminalia catappa Linn): compostos bioativos, atividade antioxidante e aplicação tecnológica, Programa de Pós-Graduação em Alimentos e Nutrição - PPGAN Teresina, 2012.

MAHAN LK, ESCOTT-STUMP S. Krause: alimentos, nutrição e dietoterapia. 10. ed.São Paulo: Roca, 2002. 1179p.

MARQUES M. R., PAZ D. D., BATISTA L. P. R., BARBOSA C. de O., ARAÚJO M. A. M., MOREIRA-ARAÚJO R. S. dos R. Composição física, físico-química, química, análise do teor de fenólicos totais e poder antioxidante in vitro de frutos de Castanhola (Terminalia catappa Linn);

Ciências Tecnologia Alimentos, Campinas, 32(1): 209-213, jan.-mar. 2012

MORAES, R. R. de. Refratometria. Governo do estado do Piauí. FAPEPI, 2006. Disponível em http://www.fapepi.pi.gov.br. Acessado em julho de 2008.

PETERSON, M. S.; Johnson, A. H. Encyclopedia of food science, vol.2.p.100-125, 1978.

SGABIERI, W.C. Alimentação e nutrição: fator de saúde e desenvolvimento. /Almed, 1987.

SILVA, M.N.F.; VALENTE, M.C. Flora da Reserva Ducke, Amazonas, Brasil: Combretaceae. Rodriguésia, Rio de Janeiro, v. 56, n. 86, p. 131-140. 2005.

SOUTO, P. C.; SALES, F. C. V.; SOUTO, J. S.; SANTOS, R. V.; SOUSA, A. A. Biometria de frutos e número de sementes de Calotropis procera (Ait.) R. Br. no semiárido da Paraíba. Revista Verde, v.3, n.1, p.108-113, 2008.

TEIXEIRA, H. L. Dissertação de mestrado: Composição Química e Perfil de Ácidos Graxos da Castanha do Fruto da Castanhola (Terminalia catappa Linn). Programa de Pós-Graduação em Engenharia de Alimentos, Área de Concentração em Engenharia de Alimentos. Itapetinga: Universidade Estadual do Sudoeste da Bahia, 60 fl, 2010.

Território do Curimataú: Resumo Executivo Plano Territorial de Desenvolvimento Rural Sustentável - PTDRS Território do Curimataú-PB. Paraíba, 2010. Disponível em: <www.http://sit.mda.gov.br/download/ptdrs/ptdrs_qua_territorio160.pdf>. Acesso: 25 ago. 2015. 